\title{
Impostores, correferência e concordância em português brasileiro
}

\author{
Imposters, coreference and agreement in Brazilian Portuguese
}

\author{
Danniel da Silva Carvalho* \\ Dorothy Brito
}

Resumo

Este trabalho aborda o fenômeno dos impostores em português brasileiro, expressões referenciais utilizadas para denotar o falante e/ou o ouvinte, cuja principal descrição foi feita por Collins e Postal (2012). A concordância pronominal com sintagmas determinantes impostores é sujeita à variação interlinguística, que será ilustrada no presente trabalho a partir de uma descrição do português brasileiro. Assumimos com Das (2014) que o sistema de flexão verbal de uma língua é fator crucial de restrição para as possibilidades de concordância pronominal. Mais especificamente, se a categoria pessoa é abertamente marcada no verbo finito, então concordância verbal com uma fonte secundária é sintaticamente bloqueada. Esta hipótese leva em conta a reestruturação do paradigma flexional do português brasileiro apontado por Duarte (1993). Os exemplos envolvendo concordância pronominal ilícita (DAS, 2014) mostram violação do princípio da homogeneidade. Por fim, testamos a hipótese com dados do italiano, língua românica com paradigma flexional verbal semelhante ao português brasileiro.

Palavras-chave: Pronomes; impostores; concordância; português brasileiro.

\section{Abstract}

This paper is concerned with the imposter phenomenon in Brazilian Portuguese, referential expressions used to denote the speaker and/or the hearer, which main description has been made by Collins and Postal (2012). Pronominal agreement with imposter determiner phrases is subject to cross-linguistic variation, which is illustrated herein with descriptive study of the relevant facts from Brazilian Portuguese. We assume with Das (2014) that the verbal agreement system of a language is the crucial factor that constrains pronominal agreement possibilities. More specifically, if the category person is overtly marked on the finite verb, then pronominal agreement with a secondary source is systematically blocked. This hypothesis takes into account the inflection paradigm restructuring in Brazilian Portuguese, as pointed out by Duarte (1993). The examples involving illicit pronominal agreement (DAS, 2014) are shown to violate the homogeneity principle. Lastly, we tested the hypothesis against data from Italian, a Romance language which shares a similar inflectional verbal paradigm with Brazilian Portuguese.

Keywords: Pronouns; imposters; agreement; Brazilian Portuguese.

* Universidade Federal da Bahia

** Universidade Federal Rural de Pernambuco/UAST 
D. S. Carvalho

\& D. Brito

Impostores, correferência e concordância em português brasileiro

\section{Introdução}

É de conhecimento geral que, para referir-se a si mesmo ou a seu interlocutor, o falante utiliza-se dos pronomes de $1^{\text {a }}$ pessoa do singular ou do plural (no conhecido plural de modéstia) - em português brasileiro (doravante PB), eu, nós e a gente - e de segunda pessoa do singular ou do plural - você, tu e vocês, no PB. Entretanto, esta não é a via de regra. Muitas vezes, o falante utiliza estratégias presentes em sua língua para expressar os participantes do discurso sem obediência à padronização pronominal paradigmática. O falante pode utilizar-se, por exemplo, de pronomes participantes do discurso (1 $1^{\text {a }}$ e $2^{\text {a }}$ pessoas) para referência arbitrária, como em (1) e (2). Por outro lado, o mesmo falante pode referir-se a si mesmo através de expressões referenciais que, por definição, não participam do discurso, como em (3).

(1) Eu começo a fumar um cigarro hoje, amanhã eu experimento x. (Contexto: um agente de controle de drogas entorpecentes sendo entrevistado por um apresentador de TV)

(2) Você começa a fumar um cigarro hoje, amanhã você experimenta $\mathrm{x}$.

(3) Esse professor merece férias urgentemente.

(Contexto: um professor de Linguística dirigindo-se a sua turma e reclamando de excesso de trabalho)
Revista Letras, Curitiba, UFPR, n. 96, pp. $54-73$ jul./dez. 2017. ISSN 2236-0999 (versão eletrônica) 
Neste fenômeno, expressões referenciais são utilizadas para denotar o falante e/ou o ouvinte. Expressões como essas são encontradas em diversas línguas naturais e são chamadas por Collins e Postal (2012) de impostores ${ }^{1}$ por conta de seu "disfarce" sintático. Tal fenômeno é atestado em diversas línguas (cf. DUDLEY, 2011, 2014, para o espanhol; DAS, 2014, para o bengali; KALULLI, 2014, para o albanês; SERVIDIO, 2014, para o italiano; WANG, 2014, para o chinês; WOOD e SIGURĐSSON, 2014, para o islandês; TAYLOR, 2009, para o $\mathrm{PB}^{2}$ ). No exemplo do inglês abaixo, em (4), extraído de Siewierska (2004, p. 1), Mummy e Johnny representam, respectivamente, $1^{\text {a }}$ e $2^{\mathrm{a}}$ pessoas em um contexto em que uma mãe está se dirigindo diretamente a seu filho. Em outras palavras, (4) pode ser interpretado como "Eu vou bater em você" no diálogo estabelecido entre mãe e filho.

$$
\begin{aligned}
& \text { Mummy will spank Johnny } \\
& \text { Mamãe FUT bater Johnny } \\
& \text { "Mamãe vai bater em Johnny" }
\end{aligned}
$$

Apesar de os impostores sintáticos terem sido notados desde Jespersen (1924), poucos trabalhos de cunho formal foram feitos sobre eles até bem recentemente. Collins e Postal (2012) apontam uma série de expressões em diferentes línguas que ilustram o conjunto de impostores: pronomes de tratamento (Vossa Majestade, Madame, Senhor), expressões de subscrição (yours truly), expressões de parentesco ao dirigir-se a crianças (mamãe, papai, vovó, titia), profissões (geralmente antecedidas por pronomes demonstrativos: este repórter, esse professor), dentre outros. A partir da observação das formas tratadas por Collins e Postal (2012) como impostores, nota-se que elas só denotam participação no discurso contextualmente. Assim, mummy ou esse professor só denotarão $1^{\text {a }}$ pessoa nos exemplos acima dentro de um contexto conversacional estabelecido entre os participantes. A utilização por um falante da expressão mummy como tentativa de denotar $1^{\text {a }}$ pessoa em um diálogo que não represente uma conversa entre uma mãe e um filho causará estranheza no interlocutor, assim como o tratamento de Vossa Alteza em uma situação em que não haja um membro da família real presente 3 . Portanto, impostores denotam participantes do discurso de grupos de falantes. Assim, estes impostores representam o próprio perfil de seus membros.

Collins e Postal (2012) discutem e analisam os impostores no inglês. A característica distintiva deste tipo de sintagmas determinantes (determiner phrase no inglês - doravante DP) é que eles engatilham concordância verbal de $3^{\text {a }}$ pes1 Do inglês imposters.

$2 \mathrm{O}$ trabalho de Taylor (2009) trata sobre o estatuto pronominal de a gente no PB, mais especificamente, o autor discute a existência de dois a gente no português falado em Piripiri, no estado do Piauí, nordeste do Brasil, sendo um considerado pronome pessoal e o outro, impostor. $\mathrm{O}$ autor não discute, portanto, a caracterização do fenômeno de forma mais geral no PB, o que pretendemos com o presente trabalho.

3 Reconhecemos a utilização destas expressões em um contexto de ironia, mas isto foge à nossa proposta de análise. 
D. S. Carvalho

$\&$ D. BRITo

Impostores, correferência e concordância em português brasileiro

soa, porém apresentando referência de $1^{\mathrm{a}}$ ou $2^{\mathrm{a}}$ pessoas. Além disso, impostores plurais em inglês podem anteceder formas pronominais tanto de $3^{a}$ pessoa quanto de $1^{\mathrm{a}}$ e $2^{\mathrm{a}}$ pessoas, como ilustrado abaixo.

(5) a. (DP de $3^{\mathrm{a}}$ pessoa com referência de falante)

Daddy is ${ }^{\star}$ am sick of your tantrums.

Papai está/ ${ }^{\star}$ estou cansado de suas pirraças

b. (DP de $3^{\text {a }}$ pessoa com referência de ouvinte) Is $\quad{ }^{\star}$ Are Madam having a good time?

Está.3.sg/ ${ }^{\star}$ Está.2.sg madame tendo um bom tempo.

"A Madame está se divertindo?"

(6) a. The present authors consider themselves/ourselves to have been slandered

Os presentes autores consideram eles.REFL/nós.REFL INF ter sido difamados.

"Os presentes autores consideram terem/termos sido caluniados"

b. Mommy and Daddy are enjoying themselves/ourselves on the beach.

Mamãe e Papai estão divertindo eles.REFL/nós.REFL em a praia.

"Mamãe e Papai estão se/ ${ }^{\star}$ nos divertindo na praia"

(DAS, 2014, p. 28)

Baseados em um amplo conjunto de dados como os acima, Collins e Postal defendem a hipótese de que apesar de os impostores parecerem ser idênticos a DPs não-impostores, suas estruturas sintáticas difeririam consideravelmente de DPs não-impostores de $3^{\text {a }}$ pessoa. Mais especificamente, os autores defendem a visão de que a propriedade chave que distingue uma forma impostora de um DP não-impostor é que o último, da mesma forma que qualquer pronominal não-expletivo, possui um antecedente. Sob essa perspectiva, um impostor com referência de $1^{\text {a }}$ pessoa pode anteceder um pronominal de $1^{\text {a }}$ pessoa, uma vez que $[A U T O R]$ seria o antecedente principal de um impostor de $1^{\text {a }}$ pessoa. Em outras palavras, um impostor de $1^{\text {a }}$ pessoa e o pronominal de $1^{\text {a }}$ pessoa, compartilhando [AUTOR] estabeleceriam condição mínima de correferência. ${ }^{4} \mathrm{Da}$

Revista Letras, 4 Essa discussão será retomada na seção 2.

Curitiba, UFPR, n. 96 , pp. $54-73$ jul./dez. 2017. ISSN 2236-0999 (versão eletrônica) 
mesma forma, impostores de $2^{\mathrm{a}}$ pessoa são semelhantes a pronominais de $2^{\mathrm{a}}$ pessoa, uma vez que ambos têm [OUVINTE] como seu antecedente principal.

Tipologicamente, há três possibilidades lógicas para a concordância pronominal com um impostor antecedente: o pronome poderia apenas concordar com o antecedente principal do impostor, como em chinês, como em (7) (cf. WANG, 2014); o pronome poderia concordar com ambos impostor e seu antecedente principal, como no inglês, como em (6b) repetido abaixo em (8) (COLLINS; POSTAL, 2012); e a terceira possibilidade lógica seria concordância pronominal com o impostor apenas, como é instanciado no caso do português brasileiro, como em (9). ${ }^{5} \mathrm{O}$ trabalho aqui desenvolvido é uma tentativa de fornecer uma descrição das estruturas impostoras no PB.

(7) Laoshi $1_{1}$ kuai yao shiqu $\left\{{ }^{\star} \mathrm{ta}_{1} / \mathrm{wo}_{1}\right\}$ de naixing le. ${ }^{6}$ Professor quase ir.para perder ele/eu POSS paciência $\mathrm{ASP}^{7}$ "O professor (=eu) está prestes a perder $\left\{{ }^{*} \mathrm{sua}_{1} / \mathrm{minha}_{1}\right\}$ paciência"

(8) Mommy and Daddy are enjoying themselves/ourselves on the beach. Mamãe e Papai estão divertindo eles.REFL/nós.REFL em a praia. "Mamãe e Papai estão se/*nos divertindo na praia"

(9) Saporra foi/ ${ }^{\star}$ fui trabalhar assim mesmo.

\section{A estrutura do DP impostor}

Nesta seção, de acordo com a proposta de Collins e Postal (2012), apresentaremos um breve panorama da estrutura de um DP impostor. Como mencionado anteriormente, apesar de um DP impostor aparentar não ser um pronominal, ele é, todavia, distinto de um DP de $3^{\text {a }}$ pessoa, uma vez que ele apresenta um antecedente de $1^{\mathrm{a}}$ ou $2^{\mathrm{a}}$ pessoa. Consideremos o paralelismo entre os exemplos em (10) e $(11)^{8}$.

5 Como apontado por um parecerista anônimo, alguns falantes do PB aceitam sentenças como (i) e (ii) abaixo. Entretanto, nas variedades do PB em que os dados foram testados, as sentenças abaixo foram consideradas agramaticais.

(i) ?Os escritores aqui presentes discordamos ${ }_{i}$ da atual decisão dessa assembleia.

(ii) ?Meus filhos, [papai e mamãe] ${ }_{i}$ vamos $_{i}$ ao cinema agora para comemorar nosso aniversário de casamento.

6 Dado extraído de Wang (2014, p. 175).

7 Abreviações: POSS = possessivo; ASP = aspecto.

8 Os dados em (10) e (11) foram adaptados de Collins e Postal (2012, p. 48, ex. 2 e 3). 
D. S. Carvalho

$\&$ D. BRITo

Impostores, correferência e concordância em português brasileiro

(10) a. Eu, Nixon, irei me vingar.

b. Nós, os presentes escritores, discordamos daquele ponto.

c. Você, senhora, não deveria tentar nos derrotar.

(11) a. Nixon irá se vingar.

b. Os presentes escritores discordam daquele ponto.

c. Os subscritos propõem um número de melhorias.

d. A senhora não deveria tentar nos derrotar.

As expressões em itálico em (10), que Collins e Postal chamam de precursores, são apresentadas como sendo constituintes DPs únicos, cada um composto por um DP pronominal e uma relativa não-restritiva reduzida. $\mathrm{O}$ componente não-restritivo permanece em uma relação de predicação com o DP pronominal. Além disso, o DP precursor como um todo não é de $3^{\mathrm{a}}$ pessoa, como evidenciado pelo fato de (10) exibir a cópula de $1^{\text {a }}$ pessoa. Assim, de acordo com Collins e Postal (2012), todo pronome, incluindo indexicais, deve ter antecedente. Para o pronome precursor $e u$ em (10a), por exemplo, o antecedente é a versão singular de DP nulo, [AUTOR].

O DP precursor fornece os elementos sintáticos e semânticos necessários para criar um impostor. Por exemplo, o impostor em (11a) denota $1^{\text {a }}$ pessoa do singular, enquanto o precursor correspondente em (10a) possui uma parte pronominal realizada que cumpre precisamente esta denotação. Ainda, o componente lexical realizado do DP impostor é idêntico ao predicado nominal no DP precursor. Dada a semelhança entre o DP precursor em (10) e o impostor correspondente em (11), Collins e Postal propõem que um impostor resulta de uma deformação sintática ${ }^{9}$ de um DP precursor potencial. Em outras palavras, um rearranjo de sua estrutura sintática. Assim, Nixon é criado através da deformação de Eu, Nixon e Senhora é uma deformação de Você, Senhora, e assim por diante. Assumindo-se que precursores possuem antecedentes e o tratamento de impostores como deformações de precursores, um impostor possuiria o mesmo antecedente que seu precursor correspondente.

O DP precursor em (10a) possui a estrutura em (12). Como já mencionado, o DP precursor é um único constituinte cujos valores dos traçosphi correspondem aos do componente pronominal inicial. Por conta desta propriedade dos precursores e da assunção adicional de que todos os pronomes devem possuir antecedente, o próprio DP precursor também é antecedido, neste caso por [AUTOR]. A relação de antecedência é codificada pela seta do DP precursor ao [AUTOR]. O componente pronominal do precursor, DP2, é

Revista Letras,

Curitiba, UFPR, n. 96, pp. $54-73$ jul./dez. 2017. ISSN 2236-0999 (versão eletrônica)

9 Collins e Postal (2012, p. 67) reconhecem que a noção de deformação é uma ideia intuitiva que precisa de explicações em uma análise concreta. Para uma discussão acerca natureza da deformação sintática, cf. Collins e Postal (2012), capítulo 5. 
modificado pela sentença relativa não-restritiva reduzida que consiste no DP3 apenas.

(12) $[\mathrm{AUTOR}] \leftarrow\left[_{\mathrm{DP} 1}\left[_{\mathrm{DP} 2} \mathrm{Eu}\right]\left[\mathrm{CLAUSE}\left[_{\mathrm{DP} 3} \text { Nixon }\right]\right]\right]^{10}$

A estrutura do DP impostor que corresponde ao precursor Eu, Nixon é dada em (13). Como indicado abaixo, a deformação sintática consiste na subida do predicado nominal do DP precursor para a posição [Spec,DP] mais alta. A partir desta posição, o predicado nominal, que tem os valores dos traços-phi de $3^{\text {a }}$ pessoa do singular, determina o valor de $3^{\text {a }}$ pessoa do singular para o impostor. Além disso, este movimento também é responsável pelo fato de o núcleo pronominal do impostor ser coberto.

\section{(13) $[\mathrm{AUTOR}] \leftarrow\left[_{\mathrm{DP} 4}\left[{ }_{\mathrm{DP} 3} \mathrm{Nixon}\right]\left[\left[_{\mathrm{D}},\left[_{\mathrm{D}}\right]\left[_{\mathrm{DP} 1}\left[{ }_{\mathrm{DP} 2}\right.\right.\right.\right.\right.$ Eu $]\left[\right.$ CLAUSE $\left.\left.\left.\left.\left[_{<\mathrm{DP} 3}\right]\right]\right]\right]\right]$}

Em suma, impostores são obtidos a partir do que Collins e Postal (2012) chamam deformação sintática de um DP precursor subjacente. Como um dos resultados da deformação, o componente pronominal do DP precursor é apagado. O núcleo do DP impostor possui os traços [AUTOR] ou [OUVINTE] como seu principal antecedente. Além disso, o predicado nominal deslocado obrigatoriamente determina os valores de $3^{\text {a }}$ pessoa dos traços-phi do DP impostor. Entretanto, por conta do núcleo nocional dos DPs impostores, uma concordância pronominal alternativa é possível, como já mencionado no exemplo (6), repetido abaixo.

(6) a. The present authors consider themselves/ourselves to have been slandered.

Os presentes autores consideram eles.REFL/nós.REFL INF ter sido difamados.

"Os presentes autores consideram terem/termos sido caluniados"

b. Mommy and Daddy are enjoying themselves/ourselves on the beach. Mamãe e Papai estão divertindo eles.REFL/nós.REFL em a praia. "Mamãe e Papai estão se/*nos divertindo na praia"

A seguir, apresentaremos os dados acerca dos impostores em PB e de seu comportamento como antecedentes de pronomes ligados, reflexivos e em contextos de controle nessa língua. Os dados foram coletados através de consultas a falantes nativos do $\mathrm{PB}$ em redes sociais de relacionamento.

10 (12) e (13) foram adaptados de Collins e Postal (2012, p. 66, ex. 60 e 62). 
D. S. Carvalho

$\&$ D. BRIto

Impostores,

correferência e

concordância

em português

brasileiro

\section{Impostores em PB}

De acordo com Collins e Postal (2012, p. 217), um impostor é um DP que nocionalmente possui pessoa $\mathrm{X}$ e gramaticalmente $\mathrm{Y}, \mathrm{X} \neq \mathrm{Y}$. Muitas das expressões impostoras discutidas pelos autores no inglês traduzem-se literalmente no $\mathrm{PB}$, muitas outras possuem equivalentes próximos e algumas aparecem como exclusivas desta língua. Alguns exemplos de DPs impostores em PB são dados abaixo:

\section{(14) DPs impostores em PB ${ }^{11}$}

$1^{\text {a }}$ pessoa: esse cara, este repórter, o professor, o presente autor, a bicha (e suas variações), a corte, nomes próprios, termos de parentesco (Papai, Mamãe, Titia, Vovó e suas variações), termos de parentesco + nome próprio, a de cá (expressão típica do estado da Bahia), expressão depreciativa + aqui: o anta aqui, o imbecil aqui, o gênio aqui etc.

$2^{\text {a }}$ pessoa: pronomes de tratamento (Senhor/Senhora/Vossa Excelência etc.), o anta, o imbecil, o gênio etc, saporra (expressão típica do estado da Bahia), nomes comuns denotando alguma hierarquia (o general, a diretora, a chefe), meus senhor/minha senhora, expressões denotando carinho antecedidas por meu/minha (minha linda, meu amor), nomes próprios, termos de parentesco, principalmente no diminutivo, termos de parentesco + nome próprio etc.

Todos esses DPs podem ser usados como expressões referenciais de $3^{\text {a }}$ pessoa. Por exemplo, papai em (15) e Maria em (16) são exemplos comuns de DPs que não denotam nem o falante nem o ouvinte.

(15) Papai está cansado.

(16) Maria foi dar uma volta.

Entretanto, o DP em (15) pode ser usado pelo falante para referir-se a si e o DP em (16) pode ser usado para referir-se ao ouvinte. Em outras palavras, estes DPs permitem uma leitura de impostores, paralela àquelas dos exemplos em (5).

Papai está/ ${ }^{\star}$ estou cansado.

(18) Maria $_{2 \mathrm{gg}}$ foi dar uma volta? ${ }^{12}$

11 Todas as expressões foram testadas por falantes nativos de diversas regiões do Brasil e consideradas possíveis como expressões de referência pessoal em contextos específicos. Por exemplo, o uso de Mamãe com referência pessoal é possível em um diálogo entre mãe e filho. Já o uso de bicha com referência pessoal é possível dentro de uma comunidade de prática homossexual (cf. CARVALHO, 2016).

12 No PB praticamente não há mais distinção entre a flexão verbal de $3^{\mathrm{a}}$ e $2^{\mathrm{a}}$ pessoas do singular (cf. RODRIGUES, 1987; DUARTE, 1995; CAVALCANTE, 2001; SILVA, 2005; RUBIO,

Revista Letras, 2006; LOPES, 2008, entre outros).

Curitiba, UFPR, n. 96 , pp. $54-73$ jul./dez. 2017. ISSN 2236-0999 (versão eletrônica) 
Os exemplos acima mostram que os DPs impostores em PB determinam concordância de $3^{a}$ pessoa. Esta generalização pode ser aplicada para todos os tipos de impostores (singulares, plurais, coordenados).

Em princípio, nada impede um pronominal de ser um impostor. Collins e Postal (2012), na verdade, discutem uma série de candidatos plausíveis para impostores pronominais, isto é, pronomes cuja interpretação difere sistematicamente em relação à referência que seria esperada de seu valor de pessoa gramatical. O Nurse-we é um desses casos, e refere-se a um pronome de primeira pessoa do plural usado por uma enfermeira para denotar um único paciente ao qual está se dirigindo (cf. COLLINS; POSTAL, 2012, p. 217-128; JOSEPH, 1979). Tal impostor tem um equivalente literal em PB. Servidio (2014, p. 126-127) afirma que o mesmo fenômeno é encontrado em italiano. Da mesma forma que no italiano, no PB esses impostores pronominais tendem a ser nulos, como ilustra o exemplo em (19). ${ }^{13}$

\section{(19) Leitura Nurse-we (JOSEPH, 1979)}

a. Como estamos nos sentindo hoje?

\section{b. ${ }^{\star}$ Como nós estamos nos sentindo hoje?}

Collins e Postal (2012) analisam Nurse-we como um pronome plural com [OUVINTE ${ }^{14}$ inerentemente como seu antecedente principal. Para dar conta do valor de primeira pessoa, os autores postulam [AUTOR] como uma fonte secundária, consequentemente com concordância de primeira pessoa.

Um outro tipo de impostor pronominal, também discutido em Collins e Postal (2012) para o inglês e atestado em PB, é o você genérico, já ilustrado aqui no dado em (2), repetido abaixo:

(2) Você começa a fumar um cigarro hoje, amanhã você experimenta $\mathrm{x}$.

No dado em (2), o sujeito de segunda pessoa do singular não se refere ao ouvinte especificamente. Antes, o pronome de segunda pessoa significa essencialmente que alguém pode começar a fumar e em seguida experimentar outras drogas. Este fato, segundo Collins e Postal (2012), suscita a possibilidade de o você genérico ser um pronome impostor.

13 As sentenças Nurse-we no PB em (19) foram testadas com falantes nativos do PB e aceitas, como as realizadas nos contextos enfermeiro(a)-paciente sem a presença de um sujeito pronominal realizado. Entretanto, reconhecemos que o fenômeno carece de uma investigação de caráter quantitativo, uma vez que é reconhecida uma tendência na língua para o preenchimento da posição sujeito (cf. DUARTE, 1993).

14 Os traços estipulados pelos autores foram traduzidos por nós. No original, [ADDRESSEE] e [AUTHOR]. 
D. S. Carvalho

$\&$ D. BRITo

Impostores,

correferência e

concordância

em português

brasileiro

Entretanto, diferentemente do inglês, este pronome genérico pode assumir a forma de qualquer outro pronome pessoal, inclusive a primeira pessoa do singular, como o exemplo em (1), repetido abaixo, ilustra. Esta mesma possibilidade ocorre com o pronome a gente. ${ }^{15}$

(1) Eu começo a fumar um cigarro hoje, amanhã eu experimento x.

\section{Uma análise dos impostores: o princípio da homogeneidade}

Nesta seção, mostraremos que uma análise com base no Princípio da Homogeneidade, juntamente com relações estabelecidas entre traço de pessoa e flexão verbal, permite-nos capturar os fatos apresentados neste artigo sobre o PB. Consideremos, então, as sentenças do inglês em (20). ${ }^{16}$

(20) a. The present authors feel that they need to defend themselves. Os presentes autores ${ }_{i}$ sentem que eles $s_{i}$ precisam defender eles mesmos.

b. The present authors feel that we need to defend ourselves. Os presentes autores sentem que nós $s_{i}$ precisam defender nós mesmos . $_{\text {. }}$

c. ${ }^{\star}$ The present authors feel that they need to defend ourselves.

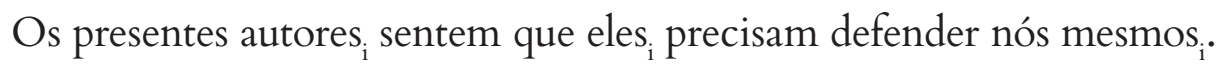

d. *The present authors feel that we need to defend themselves.

Os presentes autores, sentem que nós ${ }_{i}$ precisam defender eles mesmos.

Para explicar estes fatos e outros relacionados ao conjunto de elementos pronominais, Collins e Postal formulam o princípio da homogeneidade, definido em termos de um número de conceitos auxiliares definidos abaixo (cf. COLLINS; POSTAL, 2012, p. 143): selagem e disponibilidade.

Revista Letras,

Curitiba, UFPR, n. 96, pp. $54-73$

15 A possibilidade de os exemplos em (1) e (2) ocorrer com a primeira pessoa do plural parece restringir-se à forma a gente. No contraste em (i) e (ii), a versão com nós é considerada marginal por alguns falantes do PB se comparada com a gente. Esta restrição pode ser explicada através da Hipótese da Concordância Verbal, estipulada adiante em (28).

(i) ??Nós começamos a fumar um cigarro hoje, amanhã nós experimentamos x.

(ii) A gente começa a fumar um cigarro hoje, amanhã a gente experimenta $\mathrm{x}$.

16 Exemplos do inglês extraídos de Collins e Postal (2012, p. 141, ex. 1). 


\section{(21) Cadeia de antecedência imediata (CAI)}

Uma sequência de constituintes $\left[\mathrm{D}_{1}, \ldots, \mathrm{D}_{\mathrm{n}}\right]$ é uma cadeia de antecedência imediata sse para todo $i, 1 \leq i \leq n, \mathrm{D}_{\mathrm{i}}$ é um antecedente imediato de $\mathrm{D}_{\mathrm{i}+1}$.

No exemplo (22), o antecedente imediato de ela mesma é ela e o antecedente imediato de ela é Sheila. Desta forma, [Sheila, ela, ela mesma] constituem uma cadeia de antecedência imediata.

(22) Sheila decidiu que ela levaria ela mesma para jantar fora.

Consideremos as definições de selagem e disponibilidade propostas por Collins e Postal (2012, p. 214), vistas a partir da observação dos dados apresentados em (25).

\section{(23) Selagem}

Um DP Q é selado por $S$ em um constituinte $C$ sse $S$ e $Q$ têm um antecedente principal comum, $S$ é uma fonte primária de $Q$ e $C$ é o constituinte mínimo dominando Q e $S$.

\section{(24) Disponibilidade}

Um DP $V$ está disponível em um constituinte $C$ sse $V$ não está selado em um subconstituinte de $C .{ }^{17}$

(25) a. Ari acha que Sheila perderia o ônibus dela ${ }_{i}$.

b. Sheila ${ }_{i}$ acha que ela $a_{i}$ perderia o ônibus dela $a_{i}{ }^{18}$

c. Ari $_{\mathrm{i}}$ acha que Sheila deveria limpar o apartamento dele ${ }_{\mathrm{i}}$.

A partir da condição de selagem, em (25a), o pronome dela está selado na sentença encaixada pelo DP Sheila. Em (25b), dela está selado por ela, que, por conseguinte, não está selado na sentença encaixada, mas, mais propriamente, por Sheila na sentença matriz. Em (25c), dele não está selado na sentença encaixada, mas está selado por Ari na sentença principal. Já a partir da definição de disponibilidade, o pronome dela tanto em (25a) quanto em (25b) não estaria disponível na sentença matriz. Entretanto, em (25a), Sheila estaria disponível na sentença principal. E em (25c), tanto Ari quanto dele estariam disponíveis na sentença matriz.

17 Collins e Postal (2012, p. 244, nota de rodapé 2) definem subconstituinte de C como "um constituinte dominado por C. Note-se que nenhum constituinte é portanto um subconstituinte de si, pois, como indicado em [(i)], assumimos dominado como não reflexivo".

(i) Existência: Há uma relação de antecedência entre (ocorrências de) nós DPs que é primitiva e distinta de linearmente precedente e imediatamente dominado (mãe). Daqui por diante, assumiremos que imediatamente dominante não é reflexivo." (COLLINS; POSTAL 2012, p. 27)

$18 \mathrm{Em}(25 \mathrm{~b})$, uma leitura da cadeia ela $_{k} . .$. dela $a_{k}$ dissociada do antecedente Sheila é possível caso selagem seja violada. 
D. S. Carvalho

$\&$ D. BRITo

Impostores,

correferência e

concordância

em português

brasileiro
(26) Condição de cadeia de antecedência imediata (COLLINS; POSTAL 2012, p. 143)

Para qualquer constituinte $C$, o conjunto máximo de DPs disponíveis com o antecedente principal $U$ dominado por $C$ formam uma cadeia de antecedência imediata, chamada cadeia de U-disponibilidade em $C$.

De acordo com esta condição, para o exemplo em (25b), [Sheila, ela] é a cadeia de U-disponibilidade na sentença matriz. Considerando, então, (26), podemos assumir o princípio da homogeneidade, definido em (27) abaixo.

(27) Princípio da Homogeneidade (PH) (COLLINS; POSTAL 2012, p. 215)

Se os pronominais A e B são membros de uma mesma cadeia de U-disponibilidade, então para cada traço-phi F, cada A e B concorda com F seja com seu antecedente imediato, seja com a mesma fonte do outro.

De volta aos exemplos em (20), podemos demonstrar que as sentenças desviantes são corretamente descartadas por PH. Em (20c), por exemplo, tanto they (eles) quanto ourselves (nós mesmos) estão disponíveis na sentença encaixada, formando deste modo uma cadeia de U-disponibilidade [they, ourselves]. Entretanto, esta cadeia de U-disponibilidade particular claramente viola $\mathrm{PH}$, uma vez que ourselves não concorda com os traços-phi nem de seu antecedente imediato (they) nem com o antecedente imediato de they (the present authors), o que explica a inaceitabilidade de (20c).

A observação crucial aqui é de que o $\mathrm{PB}$, ao contrário do inglês, apresenta variedades com morfologia de concordância verbal saliente, como podemos ver nos paradigmas 1 e 2 do Quadro 1 abaixo. Para o presente trabalho, morfologia de concordância verbal saliente de uma língua será considerado qualquer paradigma verbal que apresente marcas flexionais distintas para pelo menos duas pessoas, sendo uma delas a primeira pessoa, e suas combinações com flexão de número. Esta restrição é devida, dentre outros argumentos, a evidências trazidas por Carvalho $(2008,2010,2015)$ de que a primeira pessoa é uma categoria (pronominal e flexional) mais especificada e, consequentemente, mais saliente nas línguas. Isso justifica ser a marca flexional de pessoa mais resistente nos processos de mudança nas línguas, como pode ser observado no paradigma 3 do quadro 1, para o PB, e em outras línguas, como o inglês. $\mathrm{O}$ verbo flexionado em PB é marcado por tempo, modo, pessoa e número.
Revista Letras, Curitiba, UFPR, n. 96 , pp. 54-73 jul./dez. 2017. ISSN 2236-0999 (versão eletrônica) 


\begin{tabular}{|l|l|l|l|l|}
\hline Pessoa & Número & Paradigma 1 & Paradigma 2 & Paradigam 3 \\
\hline $1^{\text {a }}$ & sing. & cant-o & cant-o & cant-o \\
\hline 2a direta & sing. & canta-s & - & - \\
\hline 2a indireta & sing. & canta-0 & canta-0 & canta-0 \\
\hline 3a & sing. & canta-0 & canta-0 & canta-0 \\
\hline 1a & plur. & canta-mos & canta-mos & canta-0 \\
\hline 2a direta & plur. & canta-is & & \\
\hline 2a indireta & plur. & canta-m & canta-m & canta-m \\
\hline 3a & plur. & canta-m & canta-m & canta-m \\
\hline
\end{tabular}

Quadro 1 - Paradigma flexional de falar no PB (DUARTE, 1993, p. 109) ${ }^{19}$

Gostaríamos de assumir com Das (2011) que a marcação pessoal realizada no verbo flexionado funciona como um elemento pronominal. Consequentemente, esta flexão verbal e os pronomes que a orbitam, se houver, estão coletivamente sujeitos ao Princípio da Homogeneidade. Isso sugere (28), adaptado de Das (2011, p. 40):

\section{(28) Hipótese da Concordância Verbal:}

A variação interlinguística na disponibilidade de concordância pronominal com uma fonte secundária é restringida pela variação no sistema da morfologia verbal. Especificamente, a concordância pronominal com uma fonte secundária é permitida apenas em línguas com morfologia verbal empobrecida. Tais relações de concordância não são alcançadas se o verbo finito carrega uma marca pessoal realizada.

À luz desta proposta, os exemplos agramaticais discutidos neste trabalho são excluídos por PH. Assim, para cada uma das sentenças malformadas, há uma cadeia de U-disponibilidade que viola PH. Para ilustrar isso, consideremos (29) abaixo. Na sentença encaixada, tanto o pronome sujeito quanto o pronominal associado à flexão verbal estão disponíveis, mesmo que nenhum deles esteja selado em nenhum subconstituinte da sentença encaixada. Duas cadeias de U-disponibilidade são possíveis: [eles, $3^{a}$ pessoa] e [nós, $3^{a}$ pessoa], das quais apenas a primeira viola $\mathrm{PH}$. A cadeia [nós, $1^{a}$ pessoa] não está disponível por ferir a Hipótese da Concordância Verbal. ${ }^{20}$ Ou seja, [eles, $3^{a}$ pessoa] constituem

19 Reconhecemos que o paradigma 1 não corresponde a nenhuma variedade falada do $\mathrm{PB}$ atualmente, mas pode ainda ser encontrado na escrita. Entretanto, manteremos o quadro extraído de Duarte (1993) para manter sua integridade com o original, o que não compromete o que queremos argumentar aqui.

20 Interessante notar que (i) abaixo, que apresenta a cadeia de U-disponibilidade [a gente, 
D. S. Carvalho

$\&$ D. BRITO

Impostores,

correferência e

concordância

em português

brasileiro

uma cadeia de U-disponibilidade e não violam o Princípio da Homogeneidade (PH), uma vez que a flexão de $3^{\text {a }}$ pessoa concorda com os traços-phi tanto de seu antecedente imediato (eles), quanto do antecedente imediato de eles (Mamãe e Papai). Já o conjunto [nós, $3^{a}$ pessoa], apesar de ser uma cadeia de U-disponibilidade, viola $\mathrm{PH}$, já que a flexão de $3^{\mathrm{a}}$ pessoa não concorda com os traços-phi de seu antecedente imediato (nós), o qual também não concorda com seu antecedente imediato (Mamãe e Papai).

(29) [ $_{\mathrm{A}}$ Mamãe e Papai decidiram que $\left[{ }_{B}\right.$ eles/*nós não vão/* vamos viajar $\left.]\right]$

Considerando (30) abaixo, a cadeia de U-disponibilidade na sentença final é dada por [PRO, deles/nossos]. Da mesma forma, a cadeia de U-disponibilidade do constituinte $\mathrm{B}$ é [estes estudantes, $3^{a}$ pessoa]. Para o constituinte $\mathrm{C}$, a cadeia de U-disponibilidade é [estes estudantes, PRO]. Assim, para a boa formação do exemplo, esta cadeia de U-disponibilidade deve obedecer $\mathrm{PH}$, o que significa que PRO é de $3^{\text {a }}$ pessoa do plural. Agora, retornando para a cadeia de U-disponibilidade no constituinte $\mathrm{A}$, temos a razão de nossos não ser possível: $\mathrm{PH}$ só é satisfeito se a cadeia de U-disponibilidade for [PRO, deles].

(30) $\quad\left[_{C}\left[_{A}\right.\right.$ Para manter os ( ${ }^{*}$ nossos) corpos deles saudáveis $\left[_{B}\right.$ estes estudantes se exercitam todos os dias]]

Consideremos agora o exemplo em (31) abaixo.

(31) [Cada um de nós $]_{\mathrm{j}}$ acha que é ${ }_{\mathrm{i}} /{ }^{\star} \operatorname{somos}_{\mathrm{i}} \mathrm{o}\left({ }^{\star} \mathrm{s}\right)$ mais talentoso $\left({ }^{\star} \mathrm{s}\right)$.

A leitura de variável ligada só está disponível com a $3^{\text {a }}$ pessoa na sentença encaixada. pro não está selado na sentença complemento. A cadeia de U-disponibilidade na sentença matriz poderia tanto ser [cada um de nós, $3^{a}$ pessoa, pro ${ }_{3}$ ] como [cada um de nós, $3^{a}$ pessoa, pro ${ }_{1 p l}$, das quais apenas o primeiro satisfaz $\mathrm{PH}$.

Por fim, consideremos (32) abaixo.

(32) $\quad\left[\right.$ Eu sou uma pessoa $\left[{ }_{B}\right.$ que cuida da sua $/{ }^{\star}$ minha saúde $\left.]\right]$

$3^{a}$ pessoa], apesar da marginalidade, tem um grau de aceitabilidade maior do que a cadeia de U-disponibilidade [nós, 1a pessoa]. Isso acontece por conta da necessidade de (i) obedecer, pelo menos sintaticamente, a hipótese em (28). Isso pressupõe uma possível hierarquia dos princípios/ hipóteses propostas neste trabalho, cuja discussão mais aprofundada vai além do escopo de nossa proposta.

Revista Letras, (i) ${ }_{A}$ Mamãe e Papai decidiram que $[$ ???a gente não vai viajar $\left.]\right]$

Curitiba, UfPR, n. 96, pp. $54-73$ jul./dez. 2017. ISSN 2236-0999 (versão eletrônica) 
Aqui, o pronome relativo que é de $3^{\text {a }}$ pessoa do singular, uma vez que o valor de seus traços-phi combina com o nome que modifica (uma pessoa). A cadeia de U-disponibilidade no constituinte B poderia ser tanto [que, sua, $3^{a}$ pessoa] quanto [que, minha, $3^{a}$ pessoa], das quais apenas a primeira satisfaz $\mathrm{PH}$.

Nesta seção, demonstramos que se assumirmos que a marca de pessoa na flexão verbal for considerada como um elemento pronominal, as sentenças em PB que violam PH são agramaticais ou, pelo menos, causam estranhamento. Esta hipótese nos permite também explicar a possibilidade de a segunda pessoa ser possível em alguns contextos, como em (33) e (34), uma vez que o paradigma flexional no PB não diferencia segundas e terceiras pessoas (cf. DUARTE, 1993).

(33) Essas desgraças cozinham só para elas/*nós/vocês mesmas.

(34) Painho e Mainha vão cozinhar só para eles/*nós/vocês mesmos.

Esta hipótese pode ser atestada em línguas de flexão verbal saliente, como o italiano. Da mesma forma que $\mathrm{PB}$, o verbo finito em italiano apresenta marcas de modo, tempo, pessoa e número, como o quadro abaixo mostra.

\begin{tabular}{|l|l|l|l|}
\hline 1 sg. & parl-o & 1 pl. & parl-iamo \\
\hline 2 sg. (f.) & parl-i & 2 pl. & parl-ate \\
\hline 2 sg. (p.) & parl-a & & \\
\hline 3 sg. & parl-a & 3 pl. & parl-ano \\
\hline
\end{tabular}

Quadro 2 - Paradigma flexional de parlare "falar" no italiano

Os impostores em italiano, de forma semelhante ao $\mathrm{PB}$ e ao inglês, engatilham concordância verbal de $3^{a}$ pessoa, como pode ser visto em (35a) e (35b). Dado o padrão de concordância verbal, podemos pressupor que, em italiano, a concordância pronominal compatibilizaria os valores dos traços-phi com os do verbo flexionado, o que é de fato confirmado, como ilustrado em (35). Este padrão de concordância pronominal é mantido também para impostores coordenados, como ilustrado em (36). ${ }^{21}$

(35) a. Gli autori cercheranno di difendere loro/se stessi

Os autores tentarão de defender eles mesmos

"Os autores tentarão se defender"

b. ${ }^{\star}$ Gli autori cercheremo di difendere noi stessi

Os autores tentaremos de defender nós mesmos

" Os autores tentaremos nos defender"

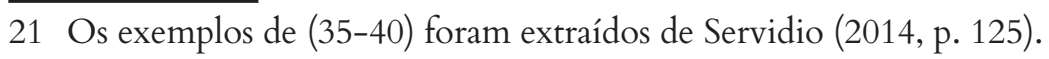


D. S. Carvalho

$\&$ D. BRITo

Impostores,

correferência e

concordância

em português

brasileiro
(36) a. Papà e mamma si prederanno cura di se stessi Papai e mamãe REFL.CL3sg tomarão conta de si mesmos "Papai e mamãe tomarão conta de si mesmos"
b. *Papà e mamma si prederanno cura di noi stessi Papai e mamãe REFL.CL3sg tomarão conta de nós mesmos “`Papai e mamãe tomarão conta de nós mesmos”

Servidio (2014) relata um número de julgamentos sutis sobre a concordância do reflexivo com o sujeito de um predicado nominal. $\mathrm{O}$ autor nota que o julgamento de aceitabilidade varia entre os diferentes valores de pessoa e número. Entretanto, os dados também mostram um padrão consistente: para qualquer cadeia de U-disponibilidade que viola $\mathrm{PH}$, a margem de degradação é menos severa para aquelas nas quais o pronome reflexivo concorda com os valores dos traços-phi do verbo flexionado que pertence à mesma cadeia de U-disponibilidade. Este fato suplementa a ideia de que a concordância verbal pode estar envolvida na mediação da concordância pronominal com fontes secundárias. Servidio (2014, p. 139) fornece os dados abaixo.

(37) a. Sono una persona che si prende cura di se stessa Sou uma pessoa que REFL.CL3sg tomar.3sg conta de si mesmo "Sou uma pessoa que toma conta de si mesmo"

Somos uma pessoa que REFL.CL1sg tomar.1sg conta de mim mesmo/a

(38) a. Sei una persona che si prende cura di se stessa

ser.2sg uma pessoa que RFL.CL3sg tomar.3sg conta de si mesma

"Você é o tipo de pessoa que toma conta de si mesmo/mesma"

b. ?* Sei una persona che ti prendi cura di te stesso/a ser.2sg uma pessoa que RFL.CL2sg tomr.2sg conta de ti mesmo/a

(39) a. Siamo persone che si prendono cura di se stesse Somos pessoas que REFL.CL3sg tomar.3pl conta de si mesmos "Somos pessoas que toma conta de nós mesmos"

b. ?Siamo persone che ci prediamo cura di noi stessi Somos pessoas que REFL.CL tomar.1pl conta de nós mesmos

(40) a. Siete persone che si predono cura di se stesse São pessoas que REFL.CL3sg tomar.3pl conta de si mesmos "Vocês são o tipo de pessoa que tomam conta de si mesmos" b. ?Siete persone che vi prendete cura di voi stessi São pessoas que REFL.CL tomar.2pl conta de vocês mesmos
Revista Letras, Curitiba, UFPR, n. 96, pp.54-73 jul./dez. 2017. ISSN 2236-0999 (versão eletrônica) 
Em primeiro lugar, as sentenças gramaticais são apenas aquelas em que a cadeia de U-disponibilidade, associada à sentença encaixada, obedece PH. Considerando (39a), por exemplo, a cadeia de U-disponibilidade relevante é dada por [che, $3^{a}$ pessoa, se stessa]. Levando em conta que o pronome relativo che tem seus valores de traços-phi compatíveis com o nome que modifica, esta cadeia de U-disponibilidade satisfaz PH. Em seguida, os exemplos em (b) são considerados marginais, mas possíveis, pois os pronomes reflexivos nestes exemplos concordam com os valores dos traços-phi dos verbos flexionados nas sentenças encaixadas. Isso sugere que a concordância verbal pode de fato desempenhar um papel na mediação das relações de concordância pronominal.

\section{Considerações finais}

Neste trabalho, apresentamos um estudo sobre o comportamento de expressões referenciais com leitura pessoal no PB para propor a sintaxe dos chamados impostores, mostrando que há um contraste na concordância pronominal com fontes secundárias nesta língua. Assumimos que as possibilidades de concordância pronominal são restringidas pelo sistema de concordância verbal. Mais especificamente, assumimos com Das (2014) que línguas em que o verbo finito é marcado morfologicamente com a categoria de pessoa desautorizam concordância pronominal com uma fonte secundária. Por fim, uma análise unificada é apresentada, na qual todos os exemplos agramaticais em PB e italiano demonstram violação do Princípio da Homogeneidade proposto por Collins e Postal (2012).

O presente trabalho apresenta um caminho para repensarmos a categoria pronominal não como uma classe fechada, como a literatura linguística sugere ser as classes funcionais, mas como uma categoria que depende de fatores contextuais (BENVENISTE, 1966) e espaço-temporais (GRUBER, 2013). Entretanto, estas considerações deverão ser objeto de investigações futuras. 
D. S. Carvalho

$\&$ D. BRITo

Impostores, correferência e concordância em português brasileiro

\section{Referências Bibliográfıcas}

BENVENISTE, É. La nature des pronoms. In: BENVENISTE, É. Problèmes de linguistique générale. Paris: Gallimard, 1966, p. 251-257.

CAVALCANTE, M.A. da S. O sujeito pronominal em Alagoas e no Rio de Janeiro: um caso de mudança em progresso. 128f. Tese (Doutorado em Linguística), Faculdade de Letras, Universidade Federal de Alagoas, Maceió, 2001.

CARVAlHO, D. S. A estrutura interna dos pronomes pessoais em Português Brasileiro. 151f. Tese (Doutorado em Linguística) - UFAL, 2008.

CARVALHO, D. S. Geometria de traços e a sintaxe de pronomes no português brasileiro. In Textos Seleccionados do XXV Encontro Nacional da Associação Portuguesa de Linguística. Lisboa: Tipografia Nunes Lda, 2010, p. 245-261.

CARVALHO, D. S. Sobre pessoa e referencialidade no português. Revista Letras, Curitiba, n. 91, p. 131-157, JAN./JUN. 2015.

CARVALHO, D. S. Person as a case of indexicalization in Brazilian Portuguese. In: 49th Annual Meeting of the Societas Linguistica Europeae, 2016, Nápoles. Handout... Nápoles: University of Naples Federico II, Itália, setembro de 2016.

COLLINS, C.; GUITARD, S.; WOOD, J. Imposters: An Online Survey of Grammaticality Judgments. NYU Working Papers in Linguistics, v. 2, 2009. Disponível em http://inguistics.as.nyu.edu/docs/CP/2345/collins_guitard_ wood_imposters_online_09_nyuwpl2.pdf. Acesso em: 06 de julho e 2016.

COLLINS, C.; POSTAL, P. Imposters: A Study of Pronominal Agreement. Cambridge, MA: MIT Press, 2012.

COLLINS, C. Cross-Linguistic Studies of Imposters and Pronominal Agreement. New York: Oxford University Press, 2014.

DAS, S. (Il)-licit Pronoun-Antecedent Relations in Bangla. In: COLLINS, C. (Ed.). Cross-Linguistic Studies of Imposters and Pronominal Agreement. New York: Oxford University Press, p. 28-41, 2014.

DUDLEY, R. An investigation of Spanish imposters and verbal agreement. 44f. Tese (Senior Honor) - Departamento de Linguística, New York University, 2011.

DUDLEY, R. Spanish imposters and verbal agreement. In: COLLINS, C. (Ed.). Cross-Linguistic Studies of Imposters and Pronominal Agreement. New York: Oxford University Press, p. 42-70, 2014.

DUARTE, M.E.L. A perda do princípio "Evite pronome" no português brasileiro. 151f. Tese (Doutorado em Linguística) - Instituto de Estudos da Linguagem, Universidade Estadual de Campinas, Campinas, 1995.
Revista Letras, Curitiba, UFPR, n. 96 , pp. 54-73 jul./dez. 2017. ISSN 2236-0999 (versão eletrônica) 
DUARTE, M.E.L. Do pronome nulo ao pronome pleno: a trajetória do sujeito no português do Brasil. In: I. Roberts, e M. Kato (Eds.), Português Brasileiro: uma viagem diacrônica. Campinas, Ed. da Unicamp, 1993, p. 107-128.

GRUBER, B. The spatiotemporal dimensions of person: A morphosyntactic account of indexical Pronouns. 267f. Tese (Doutorado em Linguística) - LOT Dissertation Series, Utrecht University, 2013.

JESPERSEN, O. The philosophy of grammar. Londres: George Allen and Unwin, 1924.

JOSEPH, B. On the agreement of reflexive forms in English. Linguistics, v. 17, n. 5-6, p. 519-523, jan. 1979.

KALLULLI, D. Some observations on imposters in Albanian. In: COLLINS, C. (Ed.). Cross-Linguistic Studies of Imposters and Pronominal Agreement. New York: Oxford University Press, 2014, p. 71-88.

KAYNE, R. The antisymmetry of syntax. Cambridge, MA: MIT Press, 1994.

LOPES, C. R. dos S. Retratos da variação entre "você" e "tu" no português do Brasil: sincronia e diacronia. In: RONCARATI, C.; ABRAÇADO, J. (Eds.). Português Brasileiro II - contato lingüístico, heterogeneidade e história. 1 ed. Niterói: EDUFF, v. 2, 2008, p. 55-71.

PODOBRYAEV, A. Persons, imposters, and monsters. 120f. Tese (Doutorado em Linguística) - Departamento de Linguística e Filosofia, Massachusetts Institute of Tecnology, 2014.

RODRIGUES, A.C.de S. A concordância verbal no português popular de São Paulo. Tese (Doutorado em Língua Portuguesa) - Faculdade de Filosofia, Letras e Ciências Humanas, Universidade de São Paulo, 1987.

RUBIO, C.F. Padrões de concordância e de alternância pronominal em português brasileiro e no português europeu: um estudo sociolinguístico comparativo. São Paulo: Cultura Acadêmica, 2012.

SERVIDIO, E. Imposters and Secondary Sources in Italian. In: COLLINS, C. (Ed.). Cross-Linguistic Studies of Imposters and Pronominal Agreement. New York: Oxford University Press, 2014, p. 121-143.

SIEWIERSKA, A. (2004). Person. Cambridge: Cambridge University Press, 2004.

SILVA, J.A.A. A concordância verbal de terceira pessoa do plural no português popular do Brasil: um panorama sociolinguístico de três comunidades do interior do estado da Bahia. 323f. Tese (Doutorado em Letras) - Instituto de Letras, Universidade Federal da Bahia, Salvador, 2005. 
D. S. Carvalho

\& D. BRITO Impostores, correferência e concordância em português brasileiro
TAYLOR, M. (2009). On the pronominal status of Brazilian Portuguese 'a gente', NYU Working Papers in Linguistics, v. 2, 2009. Disponível em http:// linguistics.as.nyu.edu/docs/CP/2345/taylor_09_a_gente_nyuwpl2.pdf. Acesso em: 06 de julho de 2016.

WANG, C.A. Mandarin Pseudo-Imposters. In: COLLINS, C. (Ed.). CrossLinguistic Studies of Imposters and Pronominal Agreement. New York: Oxford University Press, 2014, p. 173-195.

WOOD, J.; SIGURĐSSON, E.F. Icelandic verbal agreement and pronounantecedent relations. In: COLLINS, C. (Ed.). Cross-Linguistic Studies of Imposters and Pronominal Agreement. New York: Oxford University Press, 2014, p. 196258.

Submetido em: 31-02-2017

Aceito em: 15-06-2017 